\title{
EL PAPEL DE LA INFORMACIÓN GEOGRÁFICA EN EL PATRIMONIO CULTURAL INMUEBLE: CASO PRÁCTICO DE ESTUDIO DE LAS FORTIFICACIONES MEDIEVALES DE LA CUENCA DEL RÍO HENARES EN LA PROVINCIA DE GUADALAJARA (ESPAÑA)
}

\author{
María del Mar Gamo Salas \\ Escuela Técnica Superior de Ingenieros en Topografía, Geodesia y Cartografía, Universidad Politécnica de Madrid \\ margamosalas@gmail.com
}

\section{RESUMEN}

A lo largo de la historia, las distintas civilizaciones del mundo han ido dejando sus huellas a las generaciones venideras. Ese legado otorgado presenta una fuerte vinculación con el lugar en el que se establecieron dichas culturas. El presente trabajo analiza cómo el ser humano actual comprende ese vínculo entre el patrimonio cultural inmueble y su localización geográfica, y qué valor le asigna. Este análisis se ha realizado aplicado a una muestra significativa ubicada en el Reino de España: las fortificaciones medievales de la cuenca del río Henares en la provincia de Guadalajara.

Palabras clave: patrimonio cultural inmueble, fortificaciones medievales, castillos medievales, arquitectura fortificada medieval, información geográfica, localización geográfica.

\section{ABSTRACT}

During the course of history, different world civilizations have left their traces for future generations. That conferred legacy presents a strong link to the place where the aforementioned cultures were settled. The present paper analyzes how the current human

Fecha de recepción: octubre 2015.

Fecha de aceptación: abril 2017. 
being understands that link between immovable cultural heritage and its geographic location, and what value he assigns to it. This analysis has been developed applied to a significant sample located in the Kingdom of Spain: Medieval fortifications of the Henares river basin in the province of Guadalajara.

Keywords: immovable cultural heritage, medieval fortifications, medieval castles, medieval fortified architecture, geographic information, geographic location.

\section{INTRODUCCIÓN}

Los orígenes de la información geográfica están asociados al surgimiento primario de la cognición que conformó el ser humano, hace aproximadamente unos 40.000 años, y lo diferenció del resto de los primates (Malcolm Lewis, 1987). Este conocimiento le dotó al hombre prehistórico de capacidad para esquematizar en su mente las imágenes que percibía visualmente del entorno que le rodeaba y materializar esos esquemas a través del lenguaje gráfico (Malcolm Lewis, 1987) en rocas talladas (Rennie Short, 2003: 26-29). De aquí se desprende la necesidad del ser humano de conocer y controlar el territorio (Fuson, 1969; Scott Keltie y Howarth, 1913: 1-7; Varela Agüí, 2002: 109-110), que es inherente a su naturaleza de supervivencia (Malcolm Lewis, 1987; Rennie Short, 2003: 208-209; Swift, 2006: 8), la cual ha sido, y actualmente sigue siendo, común a todas sus generaciones distribuidas en toda la Tierra durante el transcurso del tiempo (Ehrenberg, 2006: 8-9; Rubiella Romañach, 2014: 29-30). Su objetivo se basa en localizar los fenómenos naturales y culturales de un espacio específico, y en establecer sus relaciones mutuas (Box, 1999: 205; Instituto Geográfico Nacional, 2008: 192-201; Swift, 2006: 11-16). Este propósito ha permanecido invariable a lo largo de la historia de la humanidad independientemente del contexto considerado: político, comercial, militar, catastral, administrativo, religioso, etcétera (Harley y Woodward, 1987: 506-509). En ese marco, la geografía se erige como la ciencia que estudia dicho objetivo (Instituto Geográfico Nacional, 2008: 192-201) y la cartografía la que lo materializa (Harley, 1987: 1-5). Por tanto, geografía y cartografía convergen en un mismo fin con un rasgo característico: la localización (Instituto Geográfico Nacional, 2008: 192-201).

La localización geográfica de un punto de la Tierra (situado encima, debajo o en su superficie) puede describirse mediante coordenadas (Asociación Española de Normalización y Certificación, 2010). Esta descripción de la posición geográfica se conoce como referencia espacial por coordenadas (Instituto Panamericano de Geografía e Historia, 2014; International Organization for Standardization, 2003a) o referencia espacial directa (Sevilla de Lerma et al., 2008). Para que esta ubicación sea inequívoca es preciso definir el sistema de referencia de coordenadas al cual están referidas dichas coordenadas (Asociación Española de Normalización y Certificación, 2010; International Organization for Standardization, 2003a). La falta de especificación del sistema de referencia de coordenadas puede conllevar grandes errores en el posicionamiento geográfico de un punto (Asociación Española de Normalización y Certificación, 2010). Asimismo, en nuestra vida cotidiana comúnmente indicamos localizaciones geográficas, cuando por ejemplo expre- 
samos la dirección de una vivienda o al indicar dónde se encuentra un lugar específico estableciendo relaciones relativas a referencias geográficas conocidas (Sevilla de Lerma et al., 2008). Esta manera de describir la posición geográfica se denomina referenciación espacial basada en identificadores geográficos o referenciación espacial indirecta (International Organization for Standardization, 2003b; Sevilla de Lerma et al., 2008). Al igual que en el caso directo, para poder establecer este tipo de posicionamiento es necesario definir el sistema de referencia al que se van a referir las posiciones que se desean determinar (Rodríguez Pascual et al., 2006; Sevilla de Lerma et al., 2008). Ambas formas de referenciación espacial (directa/indirecta) pueden aplicarse tanto a información gráfica como textual (International Organization for Standardization, 2003a; International Organization for Standardization, 2003b).

La necesidad humana de control y pertenencia a un lugar conlleva a las distintas civilizaciones de la historia a establecerse en diferentes emplazamientos geográficos de la Tierra e identificarlos como suyos (Velasco, 2009: 65-66), por lo que los productos de estas sociedades, tanto materiales como inmateriales, pasan a tener también una estrecha vinculación con la ubicación en la que se generan (Parcero-Oubiña et al., 2013: 464). En el caso de los bienes patrimoniales inmuebles, esta conexión es físicamente perceptible y patente debido a su carácter estático (Bosque González et al., 2014: 8).

Estos productos constituyen patrimonio cultural, es decir, la herencia universal que la humanidad presente recibe de sus antepasados y que debe conservar para continuar su transmisión a las generaciones futuras (Carrera Hernández, 2009: 135; Parcero-Oubiña et al., 2013: 446; United Nations Educational, Scientific and Cultural Organization, 1972a). Esta herencia, formada por un conjunto de bienes tangibles (muebles e inmuebles) e intangibles correspondientes a las diferentes civilizaciones que han existido a lo largo del tiempo, constituye un testimonio vivo de esas sociedades lleno de significación (Bosque González et al., 2014: 7; Velasco, 2009: 65). Es por ello que adquiere un valor único e insustituible (United Nations Educational, Scientific and Cultural Organization, 1972a; United Nations Educational, Scientific and Cultural Organization, 1972b), al permitir el conocimiento de la historia de las culturas del mundo relativas a distintas épocas (Gobierno de España, 2011: 80111), y por tanto servir de instrumento para el progreso y desarrollo de la comunidad humana (Dirección General de Bellas Artes, 1970: 21-22; Gobierno de Castilla-La Mancha, 2011: 7).

Teniendo en cuenta todo lo anteriormente expuesto, y particularizando para el patrimonio cultural inmueble, se plantean las siguientes cuestiones: ¿cómo el ser humano actual, en el ejercicio de su derecho al conocimiento y disfrute de los bienes patrimoniales inmuebles que hereda del pasado y que genera en el presente, concibe la relación entre dichos bienes y la localización geográfica donde se encuentran?, ¿qué importancia le concede a esa componente espacial en su obligación de conservar y transmitir ese legado?

El objetivo de esta investigación consiste en dar respuesta a estas preguntas, es decir, en analizar y discutir el papel que tiene en la actualidad la información geográfica en el patrimonio cultural inmueble. Este fin se ha llevado a cabo bajo la consideración de los siguientes agentes: la sociedad, los organismos oficiales encargados de la conservación de dicho patrimonio, y la práctica real. 
Debido a la diversidad y extensión del patrimonio cultural inmueble mundial, para alcanzar este propósito se hace necesario seleccionar un tipo específico de esos bienes y delimitar una zona geográfica de la Tierra en la que se hallen, como caso práctico de aplicación del presente estudio.

La aportación española al patrimonio cultural de la humanidad se caracteriza por su riqueza y diversidad (Dirección General del Patrimonio Artístico y Cultural, 1976: 9; Perinat Escrivá de Romaní, 2005: 390), dentro de la cual destacan por su abundancia y significado las fortificaciones (Monreal y Tejada, 1999: 33; Villena, 2001: 20), como construcciones que han estado presentes desde la prehistoria hasta la Edad Contemporánea (Fundación Ramón Areces, 1998: 11; Rodríguez Nuere, 2014: 20-22), conformando de este modo el territorio y la historia de España (Malpica Cuello, 1998: 291; Malpica Cuello, 2003: 17; Pedraza Ruiz y Franco Valle, 2014: 200; Rubiella Romañach, 2014: 43-45). A este respecto, esas edificaciones cobran especialmente relevancia y profusión en la Edad Media por los acontecimientos históricos acaecidos en la Península Ibérica durante dicho periodo (Fundación Ramón Areces, 1998: 11; Jiménez Esteban, 1995: 46-47). De esa proliferación de fortificaciones procede el nombre de la región española de Castilla, de origen medieval (García de Paz, 2006: 11; Jiménez Esteban, 1992: 7). Esta denominación ha llegado a nuestros días en las formas "Castilla y León" y "Castilla-La Mancha" constituyendo dos comunidades autónomas del actual Reino de España (http://www.ign. es/espmap/spain_bach.htm). A la última de ellas pertenece la provincia de Guadalajara (Gobierno de España, 1982b), la cual ha ocupado una posición estratégica en la Península Ibérica desde sus primeros pobladores al estar irrigada por diversos ríos que han ejercido de agentes articuladores del territorio en base a la estrategia geopolítica de la historia (Gobierno de Castilla-La Mancha, 2011: 40; Layna Serrano, 2006: 9). Particularmente, en la Edad Media los ríos de la provincia de Guadalajara alcanzaron su máximo esplendor, en cuanto a la práctica militar se refiere, al ser vías naturales de comunicación y tránsito entre dominios territoriales, constituyendo de este modo una señalada zona de frontera (García de Paz, 2006: 11; Herrera Casado, 2000: 8). La consecuencia del clima de guerra medieval (Herrera Casado, 1988: 27; Varela Agüí, 2002: 24) en esta red hidrográfica se tradujo en la construcción de un gran número de fortificaciones a lo largo de sus cursos fluviales, entre los que destacó el río Henares por la abundancia de estas edificaciones (Fernández Madrid, 1989: 357; Herrera Casado, 2000: 25; Jiménez Esteban, 1992: 7; Jiménez Esteban, 1992-1993: 12 (vol. I)). En sus orillas se estableció la relevante ciudad de Guadalajara cuyo nombre tomó de la denominación árabe del propio río "Wad-al-Hayara", que tras la adaptación castellana del vocablo ha llegado a nuestros días como "Guadalajara" (Herrera Casado, 2000: 8; Ortiz García et al., 1998: 31-32). La importancia de este río durante la época medieval fue tal que no solamente ha dado nombre a una ciudad capital sino a toda una tierra, la provincia de Guadalajara (Herrera Casado, 2002: 23-24). Esta provincia cuenta con un tesoro patrimonial cultural cuantioso y muy variado que refleja el paso de las distintas culturas que han habitado en ella, como fruto de su localización significativa en la Península Ibérica (Herrera Casado, 1988: 26). Dentro de este patrimonio sobresalen las fortificaciones medievales por su cantidad y por el valor cultural que encierran (Herrera Casado, 2000: 7). Estas fortificaciones en conjunción con sus equivalentes en otras regiones españolas constituyen elementos únicos del patrimonio cultural inmueble mundial 
ya que combinan la superposición de culturas y en concreto presentan una característica que las diferencia del resto de fortificaciones medievales de Europa, que es la influencia temprana de diversas culturas del Próximo Oriente en su estilo arquitectónico, a raíz de su entrada en la Península Ibérica durante el medievo, y que coexistió durante varios siglos con la arquitectura autóctona fusionándose y creando unas joyas exclusivas dignas de admiración (Fundación Ramón Areces, 1998: 9, 11; Jiménez Esteban, 1995: 8; Monreal y Tejada, 1999: 12, 15, 35; Villena, 2001: 20). Sin embargo, a pesar de que España lidera con una tercera posición la Lista del Patrimonio Mundial de la UNESCO (http://whc.unesco. org/es/list/), como uno de los países con mayor número de bienes declarados, sólo una ínfima parte de las fortificaciones medievales españolas aparecen en dicha clasificación, y ninguna de ellas corresponde a la provincia de Guadalajara.

El gran desconocimiento de la riqueza e importancia del patrimonio cultural de esta provincia no solamente se limita al ámbito internacional, sino que engloba el nacional así como el regional (Herrera Casado, 1988: 13). Este olvido desafortunado unido con todo lo anteriormente explicado han sido los motores que han impulsado la selección de las fortificaciones medievales de la cuenca del río Henares en la provincia de Guadalajara (España) como muestra de aplicación de la investigación aquí presentada.

\section{METODOLOGÍA Y FUENTES}

Teniendo en cuenta la muestra anteriormente seleccionada, en este apartado se describe un procedimiento que permite alcanzar el objetivo del presente estudio, es decir, analizar cuál es el papel que actualmente desempeña la información geográfica en el patrimonio cultural inmueble, para posteriormente entablar una discusión sobre si el rol que muestran los resultados obtenidos satisface la condición biunívoca e indisoluble del binomio de estudio: "patrimonio cultural inmueble-información geográfica". Como se indicó en el epígrafe anterior, este análisis consta de tres fases caracterizadas por la intervención de tres agentes, respectivamente: la sociedad, los organismos oficiales encargados de la conservación del patrimonio cultural inmueble, y la práctica real. A continuación se describe cada una de estas fases detalladamente.

\section{II.1. Análisis del papel de la información geográfica en el patrimonio cultural inmueble desde el punto de vista de la sociedad}

El patrimonio cultural inmueble constituye un documento valioso de la historia de la humanidad (Cooper, 2005: 36; Layna Serrano, 1994: 11), cuyo conocimiento y disfrute está destinado a las generaciones presentes y futuras (Guichen, 1998: 55). Bajo esta consideración, si es la sociedad el receptor de este preciado legado, ¿por qué no considerar que ella debe ser el primer factor que valore cuál es el cometido de la información geográfica en el ámbito de dicho patrimonio? Para ese propósito, se ha considerado que el instrumento más apropiado para obtener la valoración deseada es una encuesta. Entre los distintos tipos de encuesta que se pueden plantear, se ha abogado por una que analice la respuesta de la sociedad ante el estímulo de un bien de patrimonio cultural inmueble pero que no sugestione nada respecto al elemento de estudio: la información geográfica. De este 
modo, cada individuo tiene libertad plena de expresar su reacción y los resultados podrán ofrecer desde la óptica humana si la información geográfica tiene cabida en el patrimonio cultural inmueble y cuál es su alcance.

La encuesta propuesta ha consistido en que una persona ha leído una frase y a continuación ha tenido que escribir la primera idea, pensamiento o pregunta que haya pasado por su mente de forma espontánea. La frase seleccionada ha sido: "Quiero ir a ver el Castillo de Guijosa". Analizando la frase, se observa que el emisor muestra una intención "Quiero ir a ver..." y que el complemento directo de dicha intención es un bien de patrimonio cultural inmueble que forma parte de la muestra seleccionada para esta investigación “... el Castillo de Guijosa”. Por consiguiente, queda planteado un estímulo ante el cual los seres humanos pueden reaccionar de diversas maneras, y a través del análisis de esas respuestas se podrá determinar cuál es la función que la sociedad asigna a la información geográfica en el patrimonio cultural inmueble desde su subconsciencia.

\section{II.2. Análisis del papel de la información geográfica en el patrimonio cultural inmueble desde el punto de vista de los organismos oficiales encargados de la conservación de dicho patrimonio}

La gestión del patrimonio cultural tiene como objetivo la protección de dichos bienes mediante su conservación y disfrute sostenible, tanto para las generaciones presentes como futuras (Box, 1999: 3). Para poder llevar a cabo esta finalidad, en primer lugar es necesario conocer aquello que se quiere proteger (Ad hoc Group for Inventory and Documentation within the Technical Co-operation and Consultancy Programme, 2009: 17-20; Rísquez Cuenca, 1997: 243), por lo que su punto de partida se basa en la identificación de los bienes patrimoniales culturales (Braemer, 2008: 30). Es ahí donde aparece la figura del "inventario" como el instrumento para materializar esa etapa primaria (Dirección General de Bellas Artes, 1970: 38-40). De este modo, el inventario se erige como parte esencial y crítica del proceso de gestión del patrimonio cultural (Whalen, 2013), ya que a partir de él se van a fundamentar el resto de tareas que componen esa gestión (Thornes y Bold, 1998). Esta importancia confiere al inventario la necesidad de su conservación al constituir en sí mismo un bien de patrimonio cultural (Euromed Heritage 4, 2008: 153).

Recordando lo enunciado en la introducción de este estudio, los bienes patrimoniales culturales tienen una componente espacial significativa, es decir, están vinculados a una localización geográfica que caracteriza su significado y les otorga un valor no solamente perceptible en su contexto material, sino también subjetivo (Bosque González et al., 2014: 37; Parcero-Oubiña et al., 2013: 464), como identidad de un territorio (Braemer, 2008: 31). Esta naturaleza geográfica inherente al patrimonio cultural conlleva la necesidad de su definición como elemento fundamental de su documentación, y por consiguiente de su protección, a través de la expresión precisa de su localización (Box, 1999: 4; ParceroOubiña et al., 2013: 464). Por tanto, la localización geográfica es un dato básico a incluir en un inventario de patrimonio cultural. En el caso de los bienes inmuebles, esta propiedad es claramente manifiesta (Fernández-Freire et al., 2013: 76). Así lo muestran diversos estándares y recomendaciones sobre el registro de este tipo de patrimonio, tales como los correspondientes a reconocidas instituciones internacionales que persiguen la protección 
de estos bienes, siendo algunos ejemplos, del total que existen a lo largo del mundo, los trabajos del Consejo de Europa (Bold, 1993: 12-13; Promotion of Cultural Diversity in Kosovo Team, 2012: 21-23), ICOMOS (International Council on Monuments and Sites, 1996: 51-52), y The J. Paul Getty Trust (Thornes y Bold, 1998). Estos documentos tienen la particularidad de no ser de carácter normativo, por lo que el mecanismo legislativo se introduce como requerimiento para consumar la finalidad del proceso de gestión del patrimonio cultural (Fernández-Freire et al., 2013: 76).

De acuerdo con todo lo anteriormente indicado, la presente fase tiene por objetivo analizar en los documentos legislativos, actualmente vigentes en materia de patrimonio cultural, si la información geográfica aparece reflejada como dato a incluir en los inventarios de bienes culturales inmuebles y en caso afirmativo, cómo describen estos documentos el modo en el que debe definirse esa información en dichos inventarios.

Teniendo en cuenta que la información solicitada legalmente para la documentación de estos inventarios es diferente en cada país y varía con el tiempo (Ad hoc Group for Inventory and Documentation within the Technical Cooperation and Consultancy Programme, 2009: 31-33), y considerando el caso de aplicación utilizado en esta investigación, la herramienta legislativa en este estudio se circunscribe a la señalada por el Ministerio de Educación Cultura y Deporte del Gobierno de España. Según este ministerio (Gobierno de España, 2016), la legislación vigente sobre patrimonio cultural inmueble que adquiere rango normativo de ley o decreto y que expresa el registro de estos bienes, se clasifica atendiendo a los siguientes niveles: Autonómico (Ley 4/2013, de 16 de mayo, de Patrimonio Cultural de Castilla-La Mancha); Nacional (a. Ley 16/1985, de 25 de junio, del Patrimonio Histórico Español; b. Real Decreto 111/1986, de 10 de enero, de desarrollo parcial de la Ley 16/1985, de 25 de junio, del Patrimonio Histórico Español); Internacional (a. Instrumento de Ratificación del Convenio para la Protección de los Bienes Culturales en caso de Conflicto Armado, firmado en La Haya el 14 de mayo de 1954; b. Instrumento de Ratificación del Acuerdo entre el Estado español y la Santa Sede sobre Enseñanza y Asuntos Culturales, firmado en la Ciudad del Vaticano el 3 de enero de 1979; c. Instrumento de aceptación de 18 de marzo de 1982, de la Convención sobre la Protección del Patrimonio Mundial, Cultural y Natural, hecha en París el 16 de noviembre de 1972; d. Instrumento de Ratificación del Segundo Protocolo de la Convención de La Haya de 1954 para la Protección de los Bienes Culturales en caso de Conflicto Armado, hecho en La Haya el 26 de marzo de 1999; e. Instrumento de Ratificación del Convenio Europeo para la protección del patrimonio arqueológico (revisado), hecho en La Valeta el 16 de enero de 1992).

No obstante, a los anteriores títulos legislativos hay que añadir los siguientes por las razones que a continuación se enuncian: Nacional (a. Decreto de 22 de abril de 1949 sobre protección de los castillos españoles: constituye legislación vigente específica sobre el tipo de bienes culturales inmuebles seleccionados como ejemplo práctico del presente estudio; b. Plan Nacional de Arquitectura Defensiva: el artículo treinta y cinco de la mencionada Ley 16/1985, de 25 de junio, del Patrimonio Histórico Español, declara que se formularán Planes Nacionales de Información sobre el Patrimonio Histórico Español de forma periódica para la protección de dicho patrimonio (Gobierno de España, 1985a); conforme con este artículo, los bienes culturales inmuebles correspondientes al caso de aplicación de esta investigación seguirán las directrices determinadas en el Plan Nacional de Arquitectura 
Defensiva); Internacional ("Operational Guidelines for the Implementation of the World Heritage Convention” de la UNESCO (United Nations Educational, Scientific and Cultural Organization): se trata de un documento prescriptivo para el cumplimiento de la citada "Convención sobre la Protección del Patrimonio Mundial, Cultural y Natural", hecha en París el 16 de noviembre de 1972).

Los once textos previamente recogidos se han analizado y de cada uno de ellos se han extraído los siguientes datos: 1 . Título del texto y su correspondiente referencia bibliográfica; 2. Instrumento para el registro del patrimonio cultural inmueble: se ha indicado la herramienta (inventario/catálogo etcétera) que aparece especificada en el texto para registrar este tipo de patrimonio; 3. Determinación de la localización de los bienes patrimoniales inmuebles (Sí/No): se ha señalado si en el instrumento para el registro del patrimonio cultural inmueble que aparece indicado en el texto, figura o no la localización de estos bienes como dato a incluir en dicho instrumento; 4. Tipo de referenciación espacial indicada para determinar la localización de los bienes de patrimonio cultural: se ha señalado si la referenciación espacial es directa (por coordenadas) e/o indirecta (basada en identificadores geográficos); 5. Especificación del sistema de referencia (Sí/No): se ha señalado si en el texto se indica que debe especificarse el sistema de referencia al cual están referidas las localizaciones de los bienes de patrimonio cultural, tanto si la referenciación espacial es directa como indirecta; 6. Forma indicada (textual y/o gráfica) para describir la localización de los bienes patrimoniales inmuebles.

Por tanto, a partir del análisis del contenido de los inventarios de patrimonio cultural inmueble que aparecen especificados en los textos legislativos correspondientes al patrimonio cultural de un país, se puede determinar qué relevancia se le da a la información geográfica a la hora de identificar y describir esos bienes patrimoniales culturales, y consecuentemente definir cuál es el papel que ocupa esta información en el marco legislativo de una nación.

\section{II.3. Análisis del papel de la información geográfica en el patrimonio cultural inmueble desde el punto de vista de la práctica real}

En esta última fase de la metodología planteada se ha analizado si la información geográfica aparece contemplada en los inventarios sobre patrimonio cultural inmueble confeccionados tanto por organismos oficiales como por investigadores en la materia, y cómo está definida dicha información. Considerando la muestra adoptada para esta investigación, los pasos que se han seguido para alcanzar dicha finalidad son los que se describen a continuación: 1. Selección de los inventarios más significativos; 2. Extracción de la información que a continuación se detalla de cada uno de los inventarios previamente seleccionados: a) Referencia bibliográfica de cada obra; b) Localidad donde se halla la fortificación; c) Nombre de la fortificación; d) Número de página de la obra donde figura el nombre de la fortificación o donde se haga referencia a dicha construcción; e) Localización geográfica directa (mediante coordenadas) del emplazamiento de la fortificación especificando el sistema de referencia utilizado (Sí/No: en caso afirmativo se ha indicado si dicha información es textual y/o gráfica); f) Localización geográfica directa (mediante coordenadas) del emplazamiento de la fortificación sin especificar el sistema de referencia 
utilizado (Sí/No: en caso afirmativo se ha indicado si dicha información es textual y/o gráfica); g) Localización geográfica indirecta (mediante identificadores geográficos) del emplazamiento de la fortificación especificando el sistema de referencia utilizado (Sí/No: en caso afirmativo se ha indicado si dicha información es textual y/o gráfica); h) Localización geográfica indirecta (mediante identificadores geográficos) del emplazamiento de la fortificación sin especificar el sistema de referencia utilizado (Sí/No: en caso afirmativo se ha indicado si dicha información es textual y/o gráfica); i) Observaciones (anotaciones relevantes o aclaratorias sobre las fortificaciones, así como aspectos ambiguos de las mismas); 3. Análisis de la información anteriormente adquirida, obteniendo de cada obra los siguientes datos: a) Obra (título y referencia bibliográfica); b) Número total de fortificaciones inventariadas; c) Número de fortificaciones de las que se ha indicado su localización geográfica de forma directa (mediante coordenadas), especificando el sistema de referencia y/o sin especificar el sistema de referencia; d) Número de fortificaciones de las que se ha indicado su localización geográfica de forma indirecta (mediante identificadores geográficos), especificando el sistema de referencia y/o sin especificar el sistema de referencia; e) Forma de descripción de la localización (textual y/o gráfica).

Por consiguiente, a partir de la aplicación del procedimiento explicado en esta fase se puede dictaminar qué valor realmente se le da a la información geográfica en el patrimonio cultural inmueble, bajo la consideración de un caso específico de aplicación.

Los inventarios seleccionados y utilizados en esta etapa, relativos al caso de aplicación de este estudio, han sido obtenidos de las siguientes obras: 1. Inventarios realizados por organismos oficiales: "Inventario Oficial de Arquitectura Militar Fortificada de la provincia de Guadalajara" de la Asociación Española de Amigos de los Castillos (2012), "Buscador Castillos“ de la Asociación Española de Amigos de los Castillos (2013), "Castillos de la provincia de Guadalajara" del Centro de la Fotografía y la Imagen Histórica de Guadalajara (2003), e "Inventario de protección del Patrimonio Cultural Europeo (IPCE): España-2, Monumentos de arquitectura militar: Inventario resumido" de la Dirección General de Bellas Artes (1968); 2. Inventarios realizados por diversos investigadores: "Corpus de castillos medievales de Castilla“ de Espinosa de los Monteros y Martín-Artajo Saracho (1974), "Castillos y fortificaciones de Guadalajara“ de García de Paz (2006), "Guía de los castillos de Guadalajara“ de García Marquina (1980), "Guía de Campo de los Castillos de Guadalajara: una guía para conocerlos y visitarlos" de Herrera Casado (2000), "Castillos y Fortalezas de Castilla-La Mancha: una guía para conocerlos y visitarlos" de Herrera Casado (2002), "Castillos de Guadalajara“ de Jiménez Esteban (1992-1993), "Inventario de fortificaciones de Guadalajara“ de Jiménez Esteban (2003), "Castillos de Guadalajara“ de Layna Serrano (1994), "Castillos de Guadalajara“ de Ruibal Rodríguez (1992), y “Castillos de Castilla-La Mancha” de Ruibal Rodríguez y Jiménez Esteban (1997).

Para poder seleccionar y obtener los inventarios de interés, primeramente ha sido necesario delimitar el área de estudio, esto es, la cuenca del río Henares en la provincia de Guadalajara (España), para posteriormente poder determinar si estos catálogos albergan los bienes patrimoniales culturales inmuebles deseados o no. Puede ocurrir que la bibliografía no establezca inventarios por cuencas hidrográficas de forma explícita, y en caso de hacerlo, hay que comprobar la precisión de la delimitación del área. Por norma general, 
en los catálogos de bienes de patrimonio cultural inmueble, el campo que en primer lugar indica la localización de dichos bienes es el concerniente a la organización territorial de un estado. El primer apartado del Artículo 1 de la Ley 7/1985, de 2 de abril, Reguladora de las Bases del Régimen Local (Gobierno de España, 1985b) dice: «Los Municipios son Entidades básicas de la organización territorial del Estado...». Por consiguiente, el objetivo ha consistido en determinar qué municipios de la provincia de Guadalajara pertenecen a la cuenca del río Henares. Para este fin, se ha realizado la descarga de las capas vectoriales correspondientes a los sistemas de explotación del Plan Hidrológico del Tajo (aprobado por RD 1664/1998, de 24 de julio (actualmente vigente)) de la Confederación Hidrográfica del Tajo (http://www.chtajo.es/Servicios/Paginas/DescargaDCapas.aspx), y los municipios de la provincia de Guadalajara del Instituto Nacional de Estadística (http://www.ine.es/ss/ Satellite L=0\&c=Page \&cid=1254735116596\&p=1254735116596\&pagename=Productos YServicios\%2FPYSLayout). Posteriormente, se ha llevado a cabo un análisis espacial utilizando el programa QGIS para determinar qué municipios de la provincia de Guadalajara se encuentran en la cuenca del río Henares. Puede suceder que algunos de estos municipios presenten la característica de que una parte de ellos pertenezca a la cuenca del río Henares y el resto a otra/s cuenca/s, ya que los límites de la cuenca de un río no tienen por qué coincidir con los límites de los términos municipales. De este modo, puede darse el caso de que alguna de las fortificaciones se localice en alguna de esas partes no pertenecientes a la cuenca del río Henares. Esto se puede determinar si se conoce la localización geográfica precisa de dichas fortificaciones, observando cuál de ellas queda fuera de la cuenca del río Henares. Pero para ello, es necesario que los inventarios proporcionen dicha información geográfica. En este estudio, se han incluido esos municipios limítrofes y en el siguiente epígrafe se verá si ha sido posible determinar si las fortificaciones ubicadas en ellos pertenecen o no a la cuenca de estudio.

\section{RESULTADOS}

Aplicando la metodología descrita en el apartado anterior, se han obtenido una serie de resultados correspondientes a cada una de las fases en las que se divide dicho procedimiento, los cuales se exponen a continuación.

\section{III.1. Resultados del análisis del papel de la información geográfica en el patrimonio cultural inmueble desde el punto de vista de la sociedad}

La encuesta propuesta se ha realizado tomando una muestra de la sociedad formada por 90 personas de nacionalidades y profesiones diversas, y con edades comprendidas entre 18 y 75 años, cuyas respuestas se han catalogado atendiendo a la taxonomía que se ofrece en la siguiente tabla ${ }^{1}$. Cabe señalar que de acuerdo con la índole de las respuestas, algunas de ellas se han clasificado en más de una categoría taxonómica.

1 Las respuestas de los individuos encuestados, así como su catalogación correspondiente, aparecen publicadas como apéndice de la tesis doctoral realizada por la autora del presente artículo, María del Mar Gamo Salas, en la Universidad Politécnica de Madrid, de la que es fruto la investigación aquí expuesta. 
Tabla 1

TAXONOMÍA DE LAS RESPUESTAS DE LA ENCUESTA REALIZADA

\begin{tabular}{|c|c|}
\hline Categoría & $\begin{array}{l}\text { Número de } \\
\text { respuestas }\end{array}$ \\
\hline 1. Respuestas que expresan información general sobre el castillo & 4 \\
\hline 2. Respuestas que expresan información específica sobre el castillo como: & 58 \\
\hline 2.1. Localización del castillo & 55 \\
\hline 2.2. Interés del castillo & 7 \\
\hline 2.3. Si el castillo es real o ficticio & 1 \\
\hline 2.4. Época del castillo & 1 \\
\hline 2.5. Historia del castillo & 1 \\
\hline 2.6. Vida dentro del castillo & 1 \\
\hline 2.7. Modo para llegar al castillo & 1 \\
\hline 3. Respuestas que asocian el castillo a distintas ideas como: & 15 \\
\hline 3.1. Personajes concretos & 2 \\
\hline 3.2. La Edad Media & 5 \\
\hline 3.3. Turismo y/u ocio & 4 \\
\hline 3.4. Productos alimenticios & 2 \\
\hline 3.5. Lugares concretos & 4 \\
\hline 4. Respuestas que evocan diferentes conceptos como: & 9 \\
\hline 4.1. Imágenes de castillos & 3 \\
\hline 4.2. Tiempo (clima) que acontece en el lugar donde se encuentra el castillo & 3 \\
\hline 4.3. Aspecto del castillo & 3 \\
\hline 4.4. Vida dentro del castillo & 1 \\
\hline 5. Respuestas que expresan sensaciones como: & 13 \\
\hline 5.1. Añoranza de España & 1 \\
\hline 5.2. Anhelo de buen tiempo (clima) & 1 \\
\hline 5.3. Deseo de ver el castillo & 6 \\
\hline 5.4. Complacencia sobre la intención planteada por el emisor del mensaje & 6 \\
\hline 6. Respuestas que expresan información variada sobre el mensaje del emisor como: & 13 \\
\hline 6.1. Forma de pronunciar "Guijosa" & 1 \\
\hline 6.2. Concepto de Guijosa & 3 \\
\hline 6.3. Falta de identificación del castillo & 5 \\
\hline 6.4. Desconocimiento de lo que es el Castillo de Guijosa & 2 \\
\hline 6.5. Alusión a la compañía del emisor del mensaje & 2 \\
\hline 7. Respuestas que expresan la incomprensión del mensaje del emisor & 2 \\
\hline 8. Respuestas que expresan palabras sueltas & 2 \\
\hline
\end{tabular}

Fuente: Encuesta. elaboración propia. 
Es preciso señalar que durante el desarrollo de la encuesta hasta conseguir la muestra definitiva, se han ido examinando las respuestas y se ha observado que aunque la muestra fuera aumentando, los resultados obtenidos eran proporcionalmente muy similares, independientemente de la nacionalidad, edad y profesión de los individuos participantes.

Analizando la tabla anterior, y considerando el eje central de esta investigación, se obtiene que el primer pensamiento que ha surgido en 55 de las 90 personas encuestadas $(61.1 \%$ de la muestra), de forma espontánea al leer la frase "Quiero ir a ver el Castillo de Guijosa", está relacionado con la localización geográfica del castillo. El resto de participantes (38.9\% de la muestra) han dado respuestas con un rango muy alto de variabilidad.

\section{III.2. Resultados del análisis del papel de la información geográfica en el patrimonio cultural inmueble desde el punto de vista de los organismos oficiales encargados de la conserva- ción de dicho patrimonio}

La información extraída de los textos legislativos (nivel autonómico, nacional e internacional) actualmente vigentes del Gobierno de España, en materia de patrimonio cultural inmueble que contemplan el registro de estos bienes, es la que se recoge en las tablas que siguen:

Tabla 2

NIVEL AUTONÓMICO: INFORMACIÓN OBTENIDA DE LOS DOCUMENTOS LEGISLATIVOS DEL GOBIERNO DE ESPAÑA, VIGENTES EN LAACTUALIDAD, RELATIVOS A PATRIMONIO CULTURAL INMUEBLE QUE CONSIDERAN LA DOCUMENTACIÓN DE ESTE TIPO DE PATRIMONIO

\begin{tabular}{|c|c|c|c|c|c|}
\hline Título & $\begin{array}{c}\text { Instrumento } \\
\text { para el registro } \\
\text { del patrimonio } \\
\text { cultural } \\
\text { inmueble }\end{array}$ & $\begin{array}{c}\text { Determinación } \\
\text { de la } \\
\text { localización } \\
\text { de los bienes } \\
\text { patrimoniales } \\
\text { inmuebles (Sí/ } \\
\text { No) }\end{array}$ & $\begin{array}{l}\text { Tipo de } \\
\text { referenciación } \\
\text { espacial: } \\
\text { directa (por } \\
\text { coordenadas) } \\
\text { e/o indirecta } \\
\text { (basada en } \\
\text { identificadores } \\
\text { geográficos) }\end{array}$ & $\begin{array}{l}\text { Especificación } \\
\text { del sistema de } \\
\text { referencia (Sí/ } \\
\text { No) }\end{array}$ & $\begin{array}{c}\text { Forma de } \\
\text { descripción } \\
\text { de la } \\
\text { localización } \\
\text { (textual y/o } \\
\text { gráfica) }\end{array}$ \\
\hline $\begin{array}{l}\text { Ley 4/2013, de } \\
16 \text { de mayo, } \\
\text { de Patrimonio } \\
\text { Cultural de } \\
\text { Castilla- } \\
\text { La Mancha } \\
\text { (Gobierno de } \\
\text { España, 2013) }\end{array}$ & $\begin{array}{l}\text { Catálogo del } \\
\text { Patrimonio } \\
\text { Cultural de } \\
\text { Castilla-La } \\
\text { Mancha e } \\
\text { Inventario del } \\
\text { Patrimonio } \\
\text { Cultural de } \\
\text { Castilla-La } \\
\text { Mancha }\end{array}$ & Sí & Ambigüedad & No & $\begin{array}{c}\text { Textual } \\
\text { (entorno de } \\
\text { protección); } \\
\text { Gráfica } \\
\text { (entorno de } \\
\text { protección } \\
\text { y conjuntos } \\
\text { históricos) }\end{array}$ \\
\hline
\end{tabular}

Fuente: Gobierno de España. Elaboración propia. 
Tabla 3

NIVEL NACIONAL: INFORMACIÓN OBTENIDA DE LOS DOCUMENTOS LEGISLATIVOS DEL GOBIERNO DE ESPAÑA, VIGENTES EN LAACTUALIDAD, RELATIVOS A PATRIMONIO CULTURAL INMUEBLE QUE CONSIDERAN LA DOCUMENTACIÓN DE ESTE TIPO DE PATRIMONIO

\begin{tabular}{|c|c|c|c|c|c|}
\hline Título & $\begin{array}{c}\text { Instrumento } \\
\text { para el registro } \\
\text { del patrimonio } \\
\text { cultural inmueble }\end{array}$ & $\begin{array}{c}\text { Determinación } \\
\text { de la } \\
\text { localización } \\
\text { de los bienes } \\
\text { patrimoniales } \\
\text { inmuebles (Sí/ } \\
\text { No) }\end{array}$ & $\begin{array}{c}\text { Tipo de } \\
\text { referenciación } \\
\text { espacial: } \\
\text { directa (por } \\
\text { coordenadas) } \\
\text { e/o indirecta } \\
\text { (basada en } \\
\text { identificadores } \\
\text { geográficos) }\end{array}$ & $\begin{array}{l}\text { Especificación } \\
\text { del sistema de } \\
\text { referencia (Sí/ } \\
\text { No) }\end{array}$ & $\begin{array}{c}\text { Forma de } \\
\text { descripción } \\
\text { de la } \\
\text { localización } \\
\text { (textual y/o } \\
\text { gráfica) }\end{array}$ \\
\hline $\begin{array}{l}\text { Decreto de } 22 \text { de } \\
\text { abril de } 1949 \text { sobre } \\
\text { protección de los } \\
\text { castillos españoles } \\
\text { (Gobierno de } \\
\text { España, 1949) }\end{array}$ & $\begin{array}{l}\text { Inventario } \\
\text { documental y } \\
\text { gráfico }\end{array}$ & No & - & - & - \\
\hline $\begin{array}{l}\text { Ley 16/1985, } \\
\text { de } 25 \text { de junio, } \\
\text { del Patrimonio } \\
\text { Histórico Español } \\
\text { (Gobierno de } \\
\text { España, 1985a) }\end{array}$ & Registro General & No & - & - & - \\
\hline $\begin{array}{c}\text { Real Decreto } \\
\text { 111/1986, de } \\
10 \text { de enero, de } \\
\text { desarrollo parcial } \\
\text { de la Ley 16/1985, } \\
\text { de } 25 \text { de junio, } \\
\text { del Patrimonio } \\
\text { Histórico Español } \\
\text { (Gobierno de } \\
\text { España, 1986) }\end{array}$ & $\begin{array}{c}\text { Registro General de } \\
\text { Bienes de Interés } \\
\text { Cultural }\end{array}$ & Sí & Ambigüedad & No & Ambigüedad \\
\hline $\begin{array}{c}\text { Plan Nacional } \\
\text { de Arquitectura } \\
\text { Defensiva } \\
\text { (Gobierno de } \\
\text { España, 2012) }\end{array}$ & $\begin{array}{c}\text { Inventario de bienes } \\
\text { culturales y Carta } \\
\text { de Riesgos como } \\
\text { complemento de } \\
\text { dicho inventario }\end{array}$ & Sí & Directa & Sí & $\begin{array}{c}\text { Ambigüedad } \\
\text { (inventario } \\
\text { de bienes } \\
\text { culturales); } \\
\text { Textual } \\
\text { y gráfica } \\
\text { (Carta de } \\
\text { Riesgos) }\end{array}$ \\
\hline
\end{tabular}

Fuente: Gobierno de España. Elaboración propia. 
Tabla 4

NIVEL INTERNACIONAL: INFORMACIÓN OBTENIDA DE LOS DOCUMENTOS LEGISLATIVOS DEL GOBIERNO DE ESPAÑA, VIGENTES EN LAACTUALIDAD, RELATIVOS A PATRIMONIO CULTURAL INMUEBLE QUE CONSIDERAN LA DOCUMENTACIÓN DE ESTE TIPO DE PATRIMONIO

\begin{tabular}{|c|c|c|c|c|c|}
\hline Título & $\begin{array}{l}\text { Instrumento para } \\
\text { el registro del } \\
\text { patrimonio cultural } \\
\text { inmueble }\end{array}$ & $\begin{array}{c}\text { Determinación } \\
\text { de la } \\
\text { localización } \\
\text { de los bienes } \\
\text { patrimoniales } \\
\text { inmuebles (Sí/ } \\
\text { No) }\end{array}$ & $\begin{array}{c}\text { Tipo de } \\
\text { referenciación } \\
\text { espacial: directa } \\
\text { (por coordenadas) } \\
\text { e/o indirecta (basada } \\
\text { en identificadores } \\
\text { geográficos) }\end{array}$ & $\begin{array}{c}\text { Especificación } \\
\text { del sistema de } \\
\text { referencia (Síl } \\
\text { No) }\end{array}$ & $\begin{array}{l}\text { Forma de } \\
\text { descripción } \\
\text { de la } \\
\text { localización } \\
\text { (textual y/o } \\
\text { gráfica) }\end{array}$ \\
\hline $\begin{array}{l}\text { Instrumento de } \\
\text { Ratificación del } \\
\text { Convenio para la } \\
\text { Protección de los } \\
\text { Bienes Culturales } \\
\text { en caso de Conflicto } \\
\text { Armado, firmado } \\
\text { en La Haya el } 14 \\
\text { de mayo de } 1954 \\
\text { (Gobierno de España, } \\
\text { 1960) }\end{array}$ & $\begin{array}{l}\text { Registro Internacional } \\
\text { de Bienes Culturales } \\
\text { bajo Protección } \\
\text { Especial }\end{array}$ & No & - & - & - \\
\hline $\begin{array}{c}\text { Instrumento de } \\
\text { Ratificación del } \\
\text { Acuerdo entre el } \\
\text { Estado español y la } \\
\text { Santa Sede sobre } \\
\text { Enseñanza y Asuntos } \\
\text { Culturales, firmado } \\
\text { en la Ciudad del } \\
\text { Vaticano el } 3 \text { de enero } \\
\text { de } 1979 \text { (Gobierno de } \\
\text { España, 1979) }\end{array}$ & $\begin{array}{c}\text { Catalogación del } \\
\text { patrimonio cultural de } \\
\text { la Iglesia }\end{array}$ & No & - & - & - \\
\hline $\begin{array}{c}\text { Instrumento de } \\
\text { aceptación de } 18 \text { de } \\
\text { marzo de } 1982, \text { de } \\
\text { la Convención sobre } \\
\text { la Protección del } \\
\text { Patrimonio Mundial, } \\
\text { Cultural y Natural, } \\
\text { hecha en París el } 16 \\
\text { de noviembre de } 1972 \\
\text { (Gobierno de España, } \\
\text { 1982a) }\end{array}$ & $\begin{array}{l}\text { Inventario de los bienes } \\
\text { del patrimonio cultural } \\
\text { y natural aptos para } \\
\text { ser incluidos en la } \\
\text { "Lista del patrimonio } \\
\text { mundial" }\end{array}$ & Sí & Ambigüedad & No & Ambigüedad \\
\hline
\end{tabular}




\begin{tabular}{|c|c|c|c|c|c|}
\hline $\begin{array}{c}\text { Instrumento de } \\
\text { Ratificación del } \\
\text { Segundo Protocolo } \\
\text { de la Convención } \\
\text { de La Haya de } 1954 \\
\text { para la Protección de } \\
\text { los Bienes Culturales } \\
\text { en caso de Conflicto } \\
\text { Armado, hecho en La } \\
\text { Haya el } 26 \text { de marzo } \\
\text { de } 1999 \text { (Gobierno de } \\
\text { España, 2004) }\end{array}$ & $\begin{array}{l}\text { Catálogos nacionales } \\
\text { de bienes culturales y } \\
\text { Lista Internacional de } \\
\text { Bienes Culturales bajo } \\
\text { Protección Reforzada }\end{array}$ & No & - & - & - \\
\hline $\begin{array}{l}\text { Instrumento de } \\
\text { Ratificación del } \\
\text { Convenio Europeo } \\
\text { para la protección } \\
\text { del patrimonio } \\
\text { arqueológico } \\
\text { (revisado), hecho } \\
\text { en La Valeta el } 16 \\
\text { de enero de } 1992 \\
\text { (Gobierno de España, } \\
\text { 2011) }\end{array}$ & $\begin{array}{l}\text { Inventario de } \\
\text { patrimonio } \\
\text { arqueológico }\end{array}$ & Sí & Ambigüedad & No & $\begin{array}{c}\text { Textual y } \\
\text { gráfica }\end{array}$ \\
\hline $\begin{array}{c}\text { Operational } \\
\text { Guidelines for the } \\
\text { Implementation of } \\
\text { the World Heritage } \\
\text { Convention (United } \\
\text { Nations Educational, } \\
\text { Scientific } \\
\text { and Cultural } \\
\text { Organization, 2013) }\end{array}$ & $\begin{array}{l}\text { Lista Indicativa } \\
\text { (inventario de los } \\
\text { bienes aptos para } \\
\text { su inscripción en la } \\
\text { Lista del Patrimonio } \\
\text { Mundial) y expediente } \\
\text { de propuesta de } \\
\text { inscripción (lista de los } \\
\text { bienes seleccionados } \\
\text { de la Lista Indicativa } \\
\text { propuestos para su } \\
\text { inscripción en la } \\
\text { Lista del Patrimonio } \\
\text { Mundial) }\end{array}$ & Sí & $\begin{array}{c}\text { Directa con } \\
\text { ambigüedad en la } \\
\text { delimitación del bien } \\
\text { en forma textual }\end{array}$ & $\begin{array}{c}\text { No } \\
\text { (determinación } \\
\text { de las } \\
\text { coordenadas } \\
\text { del bien; } \\
\text { delimitación del } \\
\text { bien en forma } \\
\text { textual; mapa } \\
\text { de localización } \\
\text { del bien; planos } \\
\text { y mapas de las } \\
\text { características } \\
\text { del bien); } \\
\text { Sí (mapas } \\
\text { topográficos y } \\
\text { catastrales del } \\
\text { bien) }\end{array}$ & $\begin{array}{c}\text { Textual y } \\
\text { gráfica }\end{array}$ \\
\hline
\end{tabular}

Fuente: Gobierno de España. Elaboración propia.

Analizando los datos recogidos en las tablas anteriores, se obtiene que de los 11 textos legislativos, 6 de ellos (54.5\%) señalan que hay que determinar la localización geográfica de los bienes patrimoniales inmuebles en su instrumento para el registro de este tipo de patrimonio cultural. No obstante, de esos 6 textos tan sólo 2 (33.3\%), el "Plan Nacional de Arquitectura Defensiva" y el documento redactado por la UNESCO "Operational Guidelines for the Implementation of the World Heritage Convention", indican -aunque ambos con cierta ambigüedad y disparidad- que el tipo de referenciación espacial a utilizar sea directa o por coordenadas y que hay que especificar el sistema de referencia. Los otros 4 textos de los 6 
anteriormente mencionados $(66.7 \%)$ muestran una clara ambigüedad a la hora de determinar el tipo de referenciación espacial a emplear, y no indican que hay que especificar el sistema de referencia. Por último, los 5 textos restantes del total de 11 (45.5\%), ni siquiera contemplan la necesidad de definir la información geográfica de los bienes que desean proteger.

\section{III.3. Resultados del análisis del papel de la información geográfica en el patrimonio cultural inmueble desde el punto de vista de la práctica real}

Tras realizar el análisis espacial descrito en el apartado correspondiente a la metodología de este estudio, se han obtenido un total de 132 municipios de la provincia de Guadalajara ubicados en la cuenca del río Henares, tal como muestra la siguiente imagen:

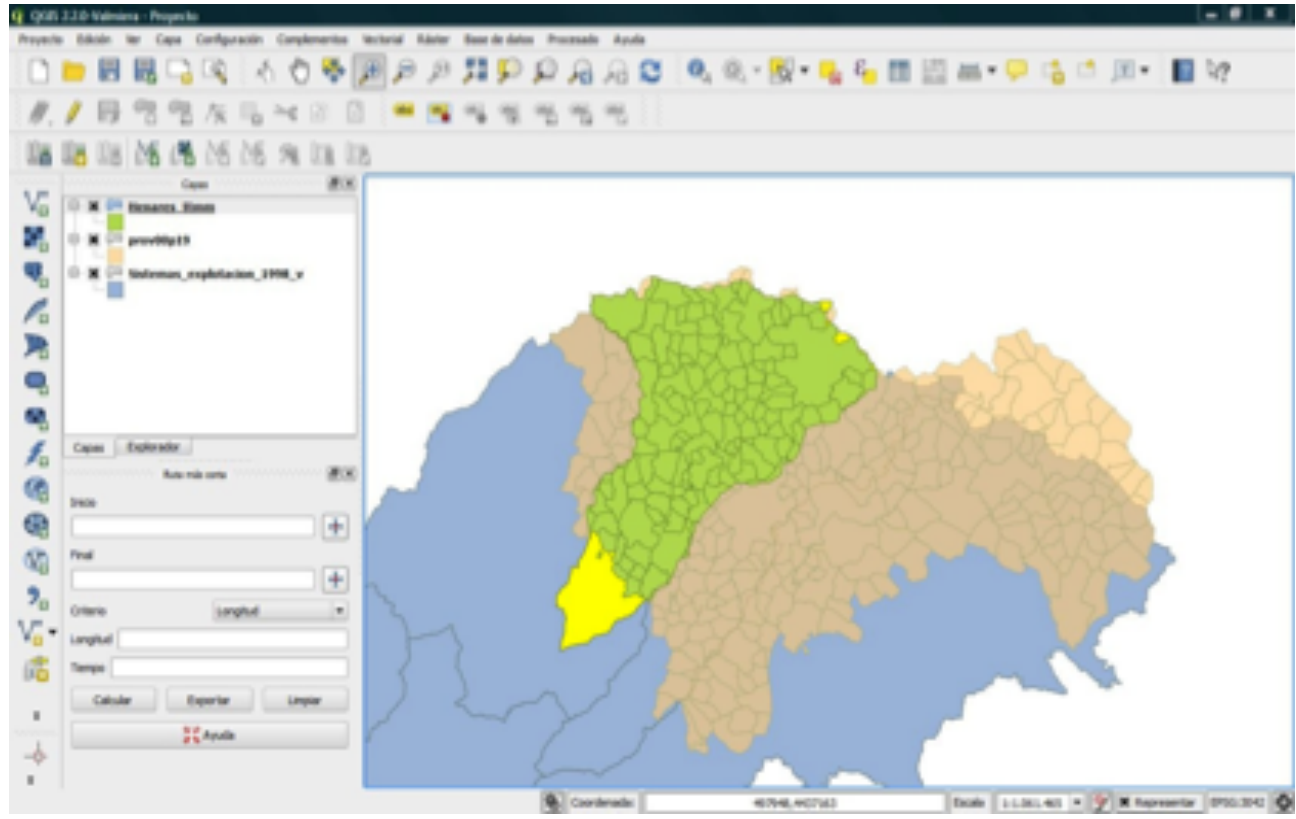

Fuente: Confederación Hidrográfica del Tajo e Instituto Nacional de Estadística. Elaboración propia.

Asimismo, como se indicó en dicho apartado, una vez determinados los anteriores municipios, se han analizado diferentes obras concernientes a fortificaciones medievales de la provincia de Guadalajara (España), desarrolladas tanto por organismos oficiales como investigadores de la materia, y se han seleccionado de ellas una serie de inventarios cuyas fortificaciones se encuentran localizadas en esos municipios. De cada uno de estos inventarios, se ha extraído la información indicada en las directrices de la metodología propuesta en esta investigación. Debido al gran volumen de los datos obtenidos, no ha sido posible incluirlos en este trabajo, pero su consulta puede realizarse en la tesis doctoral desarrollada por la 
autora del presente artículo en la Universidad Politécnica de Madrid, de la que procede la investigación aquí expuesta. Finalmente, se han analizado dichos datos conforme con el procedimiento de este estudio y se han obtenido los resultados mostrados en la siguiente tabla:

Tabla 5

RESULTADOS DEL ANÁLISIS DEL CONTENIDO DE LOS INVENTARIOS SELECCIONADOS

\begin{tabular}{|c|c|c|c|c|c|c|}
\hline \multirow{2}{*}{ Obra } & \multirow{2}{*}{$\begin{array}{l}\text { Número total de } \\
\text { fortificaciones } \\
\text { inventariadas }\end{array}$} & \multicolumn{2}{|c|}{$\begin{array}{l}\text { Número de fortificaciones de las } \\
\text { que se ha indicado su localización } \\
\text { geográfica de forma directa } \\
\text { (mediante coordenadas) }\end{array}$} & \multicolumn{2}{|c|}{$\begin{array}{l}\text { Número de fortificaciones de las } \\
\text { que se ha indicado su localización } \\
\text { geográfica de forma indirecta } \\
\text { (mediante identificadores geográficos) }\end{array}$} & \multirow{2}{*}{$\begin{array}{c}\text { Forma de descripción de } \\
\text { la localización (textual y/0 } \\
\text { gráfica) }\end{array}$} \\
\hline & & $\begin{array}{c}\text { Especificando } \\
\text { el sistema de } \\
\text { referencia } \\
\end{array}$ & $\begin{array}{c}\text { Sin especificar } \\
\text { el sistema de } \\
\text { referencia } \\
\end{array}$ & $\begin{array}{c}\text { Especificando } \\
\text { el sistema de } \\
\text { referencia } \\
\end{array}$ & $\begin{array}{c}\text { Sin especificar } \\
\text { el sistema de } \\
\text { referencia } \\
\end{array}$ & \\
\hline $\begin{array}{l}\text { Inventario de protección del Patrimonio } \\
\text { Cultural Europeo (IPCE): España-2, } \\
\text { Monumentos de arquitectura militar: } \\
\text { Inventario resumido (Dirección General } \\
\text { de Bellas Artes, 1968) }\end{array}$ & 30 & 0 & 0 & 0 & 1 & Textual \\
\hline $\begin{array}{l}\text { Corpus de castillos medievales de Castilla } \\
\text { (Espinosa de los Monteros y Martín- } \\
\text { Artajo Saracho, 1974) }\end{array}$ & 51 & 0 & 0 & 0 & 38 & $\begin{array}{l}\text { Textual ( } 32 \text { fortificaciones) } \\
\text { Textual y gráfica ( } 6 \\
\text { fortificaciones) }\end{array}$ \\
\hline $\begin{array}{l}\text { Guía de los castillos de Guadalajara } \\
\text { (García Marquina, 1980) }\end{array}$ & 15 & 0 & 0 & 0 & 15 & Textual \\
\hline $\begin{array}{l}\text { Castillos de Guadalajara (Ruibal } \\
\text { Rodríguez, 1992) }\end{array}$ & 33 & 0 & 0 & 0 & 29 & Textual \\
\hline $\begin{array}{l}\text { Castillos de Guadalajara (Jiménez } \\
\text { Esteban, 1992-1993) }\end{array}$ & 111 & 0 & 0 & 0 & 99 & $\begin{array}{l}\text { Textual ( } 83 \text { fortificaciones) } \\
\text { Textual y gráfica ( } 16 \\
\text { fortificaciones) }\end{array}$ \\
\hline $\begin{array}{l}\text { Castillos de Guadalajara (Layna Serrano, } \\
\text { 1994) }\end{array}$ & 48 & 0 & 0 & 0 & 40 & $\begin{array}{l}\text { Textual ( } 26 \text { fortificaciones) } \\
\text { Textual y gráfica ( } 14 \\
\text { fortificaciones) }\end{array}$ \\
\hline $\begin{array}{l}\text { Castillos de Castilla-La Mancha (Ruibal } \\
\text { Rodríguez y Jiménez Esteban, 1997) }\end{array}$ & 27 & 0 & 0 & 0 & 17 & Textual \\
\hline $\begin{array}{l}\text { Guía de Campo de los Castillos de } \\
\text { Guadalajara: una guía para conocerlos y } \\
\text { visitarlos (Herrera Casado, 2000) }\end{array}$ & 38 & 0 & 0 & 0 & 36 & $\begin{array}{l}\text { Textual ( } 25 \text { fortificaciones) } \\
\text { Textual y gráfica ( } 11 \\
\text { fortificaciones) }\end{array}$ \\
\hline $\begin{array}{l}\text { Castillos y Fortalezas de Castilla-La } \\
\text { Mancha: una guía para conocerlos y } \\
\text { visitarlos (Herrera Casado, 2002) }\end{array}$ & 37 & 0 & 0 & 0 & 27 & $\begin{array}{l}\text { Textual ( } 23 \text { fortificaciones) } \\
\text { Textual y gráfica ( } 4 \\
\text { fortificaciones) }\end{array}$ \\
\hline $\begin{array}{l}\text { Castillos de la provincia de Guadalajara } \\
\text { (Centro de la Fotografía y la Imagen } \\
\text { Histórica de Guadalajara, 2003) }\end{array}$ & 48 & 0 & 0 & 0 & 32 & Textual \\
\hline $\begin{array}{l}\text { Inventario de fortificaciones de Guadalajara } \\
\text { (Jiménez Esteban, 2003) }\end{array}$ & 40 & 0 & 0 & 0 & 40 & Textual \\
\hline $\begin{array}{l}\text { Castillos y fortificaciones de Guadalajara } \\
\text { (García de Paz, 2006) }\end{array}$ & 75 & 0 & 0 & 0 & 73 & $\begin{array}{l}\text { Textual ( } 52 \text { fortificaciones) } \\
\text { Textual y gráfica ( } 21 \\
\text { fortificaciones) }\end{array}$ \\
\hline $\begin{array}{l}\text { Inventario Oficial de Arquitectura Militar } \\
\text { Fortificada de la provincia de Guadalajara } \\
\text { (Asociación Española de Amigos de los } \\
\text { Castillos, 2012) }\end{array}$ & 58 & 0 & 0 & 0 & 0 & - \\
\hline $\begin{array}{l}\text { Buscador Castillos (Asociación Española } \\
\text { de Amigos de los Castillos, 2013) }\end{array}$ & 62 & 0 & 3 & 0 & 61 & $\begin{array}{l}\text { Localización geográfica } \\
\text { directa: textual. } \\
\text { Localización geográfica } \\
\text { indirecta: textual ( } 48 \\
\text { fortificaciones); gráfica ( } 1 \\
\text { fortificación); textual y gráfica } \\
\text { (12 fortificaciones) }\end{array}$ \\
\hline
\end{tabular}

Fuente: Obras citadas en la tabla. Elaboración propia. 
A excepción de las obras "Guía de los castillos de Guadalajara" de García Marquina (1980) e "Inventario de fortificaciones de Guadalajara" de Jiménez Esteban (2003), las cuales determinan la localización geográfica de todos los bienes que registran, el resto de documentos o indican la localización geográfica de casi la totalidad de los bienes inventariados ("Guía de Campo de los Castillos de Guadalajara: una guía para conocerlos y visitarlos" de Herrera Casado (2000), "Castillos y fortificaciones de Guadalajara” de García de Paz (2006), y "Buscador Castillos" de la Asociación Española de Amigos de los Castillos (2013)), o parcialmente la incluyen ("Corpus de castillos medievales de Castilla" de Espinosa de los Monteros y Martín-Artajo Saracho (1974), "Castillos de Guadalajara” de Ruibal Rodríguez (1992), "Castillos de Guadalajara" de Jiménez Esteban (1992-1993), "Castillos de Guadalajara” de Layna Serrano (1994), "Castillos de Castilla-La Mancha” de Ruibal Rodríguez y Jiménez Esteban (1997), "Castillos y Fortalezas de Castilla-La Mancha: una guía para conocerlos y visitarlos" de Herrera Casado (2002), y "Castillos de la provincia de Guadalajara" del Centro de la Fotografía y la Imagen Histórica de Guadalajara (2003)), o mínimamente la consideran como el "Inventario de protección del Patrimonio Cultural Europeo (IPCE): España-2, Monumentos de arquitectura militar: Inventario resumido" de la Dirección General de Bellas Artes (1968), o directamente no la tienen en cuenta como el "Inventario Oficial de Arquitectura Militar Fortificada de la provincia de Guadalajara" de la Asociación Española de Amigos de los Castillos (2012).

Sin embargo, en ninguna de las fortificaciones registradas de las que se ha indicado su localización geográfica (de forma directa e/o indirecta) se ha especificado el sistema de referencia utilizado, por lo que dicha información es ambigua, y por tanto, no válida, es decir, se desconoce la ubicación de estos bienes.

De este modo, se puede concluir que en la actualidad todos estos bienes inventariados carecen de información geográfica precisa y por consiguiente, no es posible localizarlos.

Debido a esta carencia, no se puede determinar cuál de estos bienes ubicados en municipios en los que una parte pertenece a la cuenca del río Henares y la otra a otra/s cuenca/s, realmente se encuentran localizados en la del Henares, esto es, no se puede delimitar con precisión la muestra del presente estudio.

\section{CONCLUSIONES}

Presentados los resultados de las tres fases metodológicas, el siguiente paso establece el debate en el que se erige este estudio: ¿es importante la información geográfica en el patrimonio cultural inmueble?

Desde el punto de vista del subconsciente humano, la respuesta a esta pregunta es afirmativa ya que la mayor parte de los sujetos encuestados $(61.1 \%)$ crean una relación entre el bien de patrimonio cultural y la localización geográfica en la que se ubica dicho bien, como reacción al estímulo planteado. Esta relación es evidente y significativa así como manifiestan la mayoría de los participantes, mientras que el resto de asociaciones (38.9\%) divergen hacia otras temáticas muy distintas. Esto pone de relieve y corrobora lo enunciado al comienzo de este estudio, esto es, independientemente del lugar y de la época en los que viva el ser humano, existe una clara inherencia entre los bienes patrimoniales culturales inmuebles y la información geográfica, de modo que estos bienes tienen un arraigo 
profundo con el lugar en el que están emplazados tanto en el plano objetivo como subjetivo: patrimonio cultural inmueble y localización geográfica son elementos indisolubles.

Sin embargo, la dicotomía surge con los organismos oficiales encargados de la conservación del patrimonio cultural inmueble y con la práctica real llevada a cabo, los cuales no terminan de compartir esa perspectiva y relegan la información geográfica a un plano secundario y en algunos casos incluso al olvido.

Así lo expresa la legislación vigente del Gobierno de España sobre patrimonio cultural inmueble de nivel autonómico, nacional e internacional, que comprende el registro de este tipo de patrimonio, la cual muestra carencias reseñables en la consideración de la localización geográfica como dato necesario y elemental a definir a la hora de documentar un bien, tal y como reflejan los resultados obtenidos en esta investigación. Conforme con estos resultados, hay una paridad porcentual aproximada entre los documentos legislativos que contemplan este tipo de información (54.5\%) y los que no (45.5\%); este hecho unido a la descripción inapropiada y pobre de dicha información por parte de los primeros, con ambigüedades y desigualdad en su determinación en todos los casos, pone de manifiesto el papel postergado que se le otorga a la información geográfica desde el instrumento legislativo en el proceso de gestión de los bienes patrimoniales inmuebles.

A esta deficiencia legisladora se une una incorrecta praxis por parte de los organismos oficiales que protegen estos bienes y de los eruditos que investigan sobre ellos. El análisis de los inventarios por ellos redactados, correspondientes a la muestra seleccionada, confirma unos resultados alarmantes: la localización geográfica de todos los bienes inmuebles inventariados es un dato desconocido, bien porque no se proporciona, bien porque se describe incorrectamente al no especificar el sistema de referencia utilizado.

Una vez analizados los roles de la información geográfica en el patrimonio cultural inmueble que asignan los distintos agentes que intervienen en su percepción, se establece el siguiente debate: si la subconsciencia humana reclama la importancia del conocimiento de la localización geográfica del patrimonio cultural inmueble, ¿por qué la naturaleza consciente del hombre la ignora?

El tema abierto es interesante y en cierta manera puede resultar controvertido, ya que como primera instancia se podrían exigir responsabilidades a las autoridades legislativas que velan por la protección de dichos bienes, seguido de una baja estimación y valoración del trabajo independiente desarrollado por investigadores de la materia. Sin embargo, nuevas preguntas emanan: si los expertos en información geográfica (geógrafos, cartógrafos, geodestas, topógrafos, etcétera) nos asustamos de los resultados de este análisis y los criticamos con rigurosidad, ¿no será el momento de hacer un examen retrospectivo de nuestra profesión?, ¿no será que no hemos transmitido adecuadamente la relevancia de la información geográfica en la gestión del patrimonio cultural inmueble?, ¿no será que no hemos defendido nuestras competencias a ese respecto en la comunidad nacional e internacional? las respuestas a todas estas preguntas son clave: si algo se está haciendo incorrectamente es porque los responsables correspondientes no están controlando y explicando la manera conveniente de proceder, pero la responsabilidad principal no recae en las entidades oficiales o investigadores, sino en la colectividad profesional de información geográfica (asociaciones, institutos, organismos reguladores, etcétera), ya que no estamos defendiendo nuestra experiencia y conocimiento, tanto en el plano nacional como internacional, y por tanto no la estamos dando a conocer. 
Obviamente, nuestra acción promotora aislada no es suficiente y debe ser complementada con legislación que instruya la consecución efectiva de protección de este tipo de patrimonio mediante la consideración de la información geográfica a nivel de facto y forma como dato fundamental a incorporar en el ejercicio de inventario de estos bienes; pero para ello, nuestra intervención es crítica y primaria.

Con esta investigación quiero expresar mi deseo de concienciación al gremio geográfico de las nefastas consecuencias para el progreso y desarrollo humano que puede conllevar una incorrecta documentación de los bienes patrimoniales culturales inmuebles en cuanto a la determinación de su localización geográfica, la cual es crucial para su conservación y transmisión a las generaciones venideras, y de este modo, aunemos nuestros esfuerzos en desarrollar planes de acción a través de los cuales le demos a la información geográfica el valor que realmente tiene: un papel protagonista en la gestión del patrimonio cultural inmueble.

"El progreso no consiste en aniquilar hoy el ayer, sino, al revés, en conservar aquella esencia del ayer que tuvo la virtud de crear ese hoy mejor", José Ortega y Gasset (Rivera Blanco, 1999: 17).

\section{BIBLIOGRAFÍA}

AD HOC GROUP FOR INVENTORY AND DOCUMENTATION WITHIN THE TECHNICAL CO-OPERATION AND CONSULTANCY PROGRAMME (2009): Guidance on inventory and documentation of the cultural heritage / Document prepared by the Ad hoc Group for Inventory and Documentation within the Technical Co-operation and Consultancy Programme related to the Integrated Conservation of the Cultural Heritage. Estrasburgo. Council of Europe Publishing.

ASOCIACIÓN ESPAÑOLA DE AMIGOS DE LOS CASTILLOS (2012): Inventario Oficial de Arquitectura Militar Fortificada de la provincia de Guadalajara. Mensaje electrónico para: Gamo Salas, M. M., 23 de Marzo de 2012. Comunicación personal. Archivo recibido: "guadalajara.xls".

ASOCIACIÓN ESPAÑOLA DE AMIGOS DE LOS CASTILLOS (2013): Buscador Castillos [en línea]. Contenido de sitio web. [Consulta: 27 de abril de 2015]. Disponible en: http://www.castillosdeespana.es/es/buscador-castillos

ASOCIACIÓN ESPAÑOLA DE NORMALIZACIÓN Y CERTIFICACIÓN (2010): UNEEN ISO 6709: Representación normalizada de localizaciones geográficas puntuales mediante coordenadas. Madrid. Asociación Española de Normalización y Certificación (AENOR).

BOLD, J. (1993): «The documentation of the architectural heritage in Europe: A progress report», en Nantes Colloquy on Inventory and Documentation Methods, Architectural heritage: inventory and documentation methods in Europe: proceedings, European colloquy organised by the Council of Europe and the French Ministry for Education and Culture - Direction du patrimoine, Nantes, 28-31 October 1992 (Council of Europe). Estrasburgo, Council of Europe Press, 11-15. Disponible en: https://www.coe.int/t/dg4/cultureheritage/heritage/resources/Publications/Pat_PA_28_ en.pdf 
BOSQUE GONZÁLEZ, I. DEL, VICENT GARCÍA, J. M., ABAD BALBOA, T., ABAD VIDAL, E., CHÍAS NAVARRO, P., CRIADO VALDÉS, M., FÁBREGA-ÁLVAREZ, P., FARJAS ABADÍA, M., FERNÁNDEZ FREIRE, C. (ED.), FRAGUAS BRAVO, A., GARCÍA CEPEDA, F., LAGE REIS-CORREIA, M., PARCERO-OUBIÑA, C. (ED.), MÁRQUEZ PIQUERAS, J., MAYORAL HERRERA, V., PECHARROMÁN FUENTE, J. L., PÉREZ ASENSIO, E., RESPALDIZA HIDALGO, A., RUIZ DEL ÁRBOL MORO, M., URIARTE GONZÁLEZ, A. (ED.), VÁZQUEZ HOENHE, A. y ZANCAJO JIMENO, J. J. (2014): A data model for Cultural Heritage within INSPIRE. Santiago de Compostela (España). Consejo Superior de Investigaciones Científicas (CSIC), Instituto de Ciencias del Patrimonio (Incipit). Disponible en: http://digital.csic.es/handle/10261/94227

BOX, P. (1999): GIS and Cultural Resource Management: A Manual for Heritage Managers. Bangkok (Tailandia). UNESCO. Disponible en:

http://unesdoc.unesco.org/images/0011/001162/116270Eo.pdf

BRAEMER, F. (2008): «Background Paper», en Euromed Heritage 4/Strengthening of Institutional and Legal Frameworks/Workshop on Inventories/Proceedings (Euromed Heritage 4). París, Euromed Heritage, 30-33. Disponible en: http://www.euromedheritage.net/ euroshared/doc/actes.pdf

CARRERA HERNÁNDEZ, J. (2009): «La UNESCO y la gestión del patrimonio mundial: mecanismos de protección y garantía», en La protección jurídico internacional del patrimonio cultural: Especial referencia a España (Fernández Liesa, C. R. y Prieto de Pedro, J. Dir., Vacas Fernández, F. y Zapatero Miguel, P., Coord.). Majadahonda (Madrid), COLEX, 135-154.

CENTRO DE LA FOTOGRAFÍA Y LA IMAGEN HISTÓRICA DE GUADALAJARA (2003): Castillos de la provincia de Guadalajara. [Guadalajara (España)]. Centro de la Fotografía y la Imagen Histórica de Guadalajara.

COOPER, E. (2005): «El respeto y el amor a las más elevadas esencias espirituales», y otros criterios en la restauración de los castillos», en Simposio Internacional «Arquitectura fortificada»: Conservación, restauración y uso de los castillos (Cooper, E., coord.). Valladolid (España), Fundación del Patrimonio Histórico de Castilla y León, 17-49.

DIRECCIÓN GENERAL DE BELLAS ARTES (1968): Inventario de protección del Patrimonio Cultural Europeo (IPCE): España-2, Monumentos de arquitectura militar: Inventario resumido. [Madrid]. Dirección General de Bellas Artes.

DIRECCIÓN GENERAL DE BELLAS ARTES (1970): Defensa del Patrimonio Artístico y Cultural de Europa (Bruselas, noviembre de 1969). Madrid. Dirección General de Bellas Artes.

DIRECCIÓN GENERAL DEL PATRIMONIO ARTÍSTICO Y CULTURAL (1976): Patrimonio monumental de España: exposición sobre su conservación y revitalización. [Madrid (España)]. Dirección General del Patrimonio Artístico y Cultural.

EHRENBERG, R. E. (ED.) (2006): Mapping the World: An Illustrated History of Cartography. Washington, D.C. National Geographic Society.

ESPINOSA DE LOS MONTEROS, J. y MARTÍN-ARTAJO SARACHO, L. (1974): Corpus de castillos medievales de Castilla. Bilbao (España). Clave.

EUROMED HERITAGE 4 (2008): «Report of the Debates», en Euromed Heritage 4/Strengthening of Institutional and Legal Frameworks/Workshop on Inventories/Proceedings (Euromed Heritage 4). París, Euromed Heritage, 145-155. Disponible en:

http://www.euromedheritage.net/euroshared/doc/actes.pdf 
FERNÁNDEZ-FREIRE, C., BOSQUE-GONZÁLEZ, I. DEL, VICENT-GARCÍA, J. M., PÉREZ-ASENSIO, E., FRAGUAS-BRAVO, A., URIARTE-GONZÁlEZ, A., FÁBREGA-ÁLVAREZ, P. y PARCERO-OUBIÑA, C. (2013): «A Cultural Heritage Application Schema: Achieving Interoperability of Cultural Heritage Data in INSPIRE». International Journal of Spatial Data Infrastructures Research, vol. 8, 74-97. Disponible en: http://ijsdir.jrc.ec.europa.eu/index.php/ijsdir/article/view/315/355

FERNÁNDEZ MADRID, M. T. (1989): «Los Castillos del Henares: planteamientos iconográficos y artísticos». Wad-Al-Hayara: Revista de Estudios de la Institución Provincial de Cultura «Marqués de Santillana» de Guadalajara, núm. 16, 357-369. Disponible en: http://biblioteca2.uclm.es/biblioteca/CECLM/ARTREVISTAS/Wad/wad16Fernandez.pdf

FUNDACIÓN RAMÓN ARECES (1998): El castillo medieval español: La fortificación española y sus relaciones con la europea. Madrid (España). Editorial Centro de Estudios Ramón Areces.

FUSON, R. H. (1969): A geography of geography: Origins and development of the discipline. Dubuque (Iowa). Wm. C. Brown Company Publishers.

GARCÍA DE PAZ, J.L. (2006): Castillos y fortificaciones de Guadalajara. Guadalajara (España). Nueva Alcarria.

GARCÍA MARQUINA, F. (1980): Guía de los castillos de Guadalajara. Guadalajara (España). Institución de Cultura "Marqués de Santillana".

GOBIERNO DE CASTILLA-LA MANCHA (ED.) (2011): Castilla-La Mancha guía de patrimonio cultural - 1. Albacete/Guadalajara. Toledo (España). Consejería de Educación, Ciencia y Cultura.

GOBIERNO DE ESPAÑA (1949): «Decreto de 22 de abril de 1949 sobre protección de los castillos españoles». Boletín Oficial del Estado, núm. 125, 2058-2059. Disponible en: https://www.boe.es/datos/pdfs/BOE/1949/125/A02058-02059.pdf

GOBIERNO DE ESPAÑA (1960): «Instrumento de Ratificación del Convenio para la Protección de los Bienes Culturales en caso de conflicto armado». Boletín Oficial del Estado, núm. 282, 16189-16194. Disponible en: http://www.mecd.gob.es/legislacionconvenio/ legislacion/boeratconfli.pdf

GOBIERNO DE ESPAÑA (1979): «Instrumento de Ratificación del Acuerdo entre el Estado español y la Santa Sede sobre Enseñanza y Asuntos Culturales, firmado en la Ciudad del Vaticano el 3 de enero de 1979». Boletín Oficial del Estado, núm. 300, 28784-28785. Disponible en: https://www.boe.es/boe/dias/1979/12/15/pdfs/A28784-28785.pdf

GOBIERNO DE ESPAÑA (1982a): «Instrumento de aceptación, de 18 de marzo de 1982, de la Convención sobre la Protección del Patrimonio Mundial, Cultural y Natural, hecho en París el 23 de noviembre de 1972». Boletín Oficial del Estado, núm. 156, 17883-17887. Disponible en: http://www.boe.es/boe/dias/1982/07/01/pdfs/A17883-17887.pdf

GOBIERNO DE ESPAÑA (1982b): «Ley Orgánica 9/1982, de 10 de agosto, de Estatuto de Autonomía de Castilla-La Mancha». Boletín Oficial del Estado, núm. 195, 22040-22047. Disponible en: http://www.boe.es/boe/dias/1982/08/16/pdfs/A22040-22047.pdf

GOBIERNO DE ESPAÑA (1985a): «Ley 16/1985, de 25 de junio, del Patrimonio Histórico Español». Boletín Oficial del Estado, núm. 155, 20342-20352. Disponible en: https://www.boe.es/boe/dias/1985/06/29/pdfs/A20342-20352.pdf https://www.boe.es/ boe/dias/1985/12/11/pdfs/A39101-39101.pdf 
GOBIERNO DE ESPAÑA (1985b): «Ley 7/1985, de 2 de abril, Reguladora de las Bases del Régimen Local». Boletín Oficial del Estado, núm. 80, 8945-8964. Disponible en: https://www.boe.es/boe/dias/1985/04/03/pdfs/A08945-08964.pdf

GOBIERNO DE ESPAÑA (1986): «Real Decreto 111/1986, de 10 de enero, de desarrollo parcial de la Ley 16/1985, de 25 de junio, del Patrimonio Histórico Español». Boletín Oficial del Estado, núm. 24, 3815-3831. Disponible en: https://www.boe.es/boe/ dias/1986/01/28/pdfs/A03815-03831.pdf

GOBIERNO DE ESPAÑA (2004): «Instrumento de Ratificación del Segundo Protocolo de la Convención de La Haya de 1954 para la Protección de los Bienes Culturales en caso de Conflicto Armado, hecho en La Haya el 26 de marzo de 1999». Boletín Oficial del Estado, núm. 77, 13410-13417. Disponible en:

http://www.mecd.gob.es/legislacionconvenio/legislacion/boe2protconflarm.pdf

GOBIERNO DE ESPAÑA (2011): «Instrumento de Ratificación del Convenio Europeo para la protección del patrimonio arqueológico (revisado), hecho en La Valeta el 16 de enero de 1992». Boletín Oficial del Estado, núm. 173, 80110-80119. Disponible en: http://www.mecd.gob.es/legislacionconvenio/legislacion/boepatarqueovaletta.pdf

GOBIERNO DE ESPAÑA (2012): Plan Nacional de Arquitectura Defensiva. [Madrid]. Gobierno de España, Ministerio de Educación, Cultura y Deporte. Disponible en: http://ipce.mcu.es/pdfs/PNArquitecturaDefensiva.pdf

GOBIERNO DE ESPAÑA (2013): «Ley 4/2013, de 16 de mayo, de Patrimonio Cultural de Castilla-La Mancha». Boletín Oficial del Estado, núm. 240, 81970-82008. Disponible en: https://www.boe.es/boe/dias/2013/10/07/pdfs/BOE-A-2013-10415.pdf

GOBIERNO DE ESPAÑA (2016): Legislación de Patrimonio Histórico. [Madrid]. Gobierno de España, Ministerio de Educación, Cultura y Deporte). Disponible en:

http://www.mecd.gob.es/legis lacionconvenio/loadSearchLegislation. do? cache=init\&legislation. area $. i d=P A H I \& l a y o u t=l e g i s l a c i o n P a t r i m o n i o \& l a n g u a g e=e s$

GUICHEN, G. DE (1998): «El Documento de Pavía: hacia un perfil europeo del conservador-restaurador». Museum Internacional, vol. 199, 55-56. Disponible en: http://unesdoc.unesco.org/images/0011/001130/113066so.pdf

HARLEY, J. B. (1987): «The Map and the Development of the History of Cartography», en The History of Cartography/Volume One: Cartography in Prehistoric, Ancient, and Medieval Europe and the Mediterranean (Harley, J. B. y Woodward, D., Eds.). Chicago, The University of Chicago Press, 1-42.

HARLEY, J. B. y WOODWARD, D. (1987): «Concluding Remarks», en The History of Cartography/Volume One: Cartography in Prehistoric, Ancient, and Medieval Europe and the Mediterranean (Harley, J. B. y Woodward, D., eds.). Chicago, The University of Chicago Press, 502-509.

HERRERA CASADO, A. (1988): Crónica y guía de la provincia de Guadalajara. Guadalajara (España). Excma. Diputación Provincial de Guadalajara.

HERRERA CASADO, A. (2000): Guía de Campo de los Castillos de Guadalajara: una guía para conocerlos y visitarlos. Guadalajara (España). Aache.

HERRERA CASADO, A. (2002): Castillos y Fortalezas de Castilla-La Mancha: una guía para conocerlos y visitarlos. Guadalajara (España). Aache. 
INSTITUTO GEOGRÁFICO NACIONAL (2008): «Cartografía y Geografía, Relaciones mutuas, Funciones de la cartografía en los estudios geográficos: inventario, referenciación, explicación, correlación, experimentación, investigación, etc., Aplicación de la cartografía en la geografía física y humana», en Temario básico y bibliografía recomendada para la preparación de la Oposición al Cuerpo de Ingenieros Geógrafos (año 2008) - Grupo E: Conocimientos avanzados en Geografía y Cartografía (Instituto Geográfico Nacional). [Madrid], Instituto Geográfico Nacional, 191-211. Disponible en: https:// www.ign.es/ign/resources/acercaDe/aig/E.pdf

INSTITUTO PANAMERICANO DE GEOGRAFÍA E HISTORIA (2014): Guía de Normas, segunda edición en español 2013, Comité ISO/TC 211 Información Geográfica/Geomática. Mexico D.F. Instituto Panamericano de Geografía e Historia. Disponible en: http://www.isotc211.org/Outreach/ISO_TC_211_Standards_Guide_Spanish_v2.pdf

INTERNATIONAL COUNCIL ON MONUMENTS AND SITES (1996): Principles for the recording of monuments, groups of buildings and sites. [París]. International Council on Monuments and Sites. Disponible en: http://www.icomos.org/charters/archives-e.pdf

INTERNATIONAL ORGANIZATION FOR STANDARDIZATION (2003a): ISO 19111:2003 (E): Información geográfica - Sistemas de referencia espaciales por coordenadas. Ginebra. ISO copyright office. Disponible en:

http://redgeomatica.rediris.es/traducciones/ISO_19111_Sistema_de_Referencia_MABP.pdf

INTERNATIONAL ORGANIZATION FOR STANDARDIZATION (2003b): ISO 19112:2003 (E): Geographic information - Spatial referencing by geographic identifiers. Ginebra. ISO copyright office. Disponible en: http://people.ischool.berkeley. edu/ ryanshaw/pdf/ISO_19112.pdf

JIMÉNEZ ESTEBAN, J. (1992): Castillos de España. [Madrid (España)]. Ediciones Rueda. JIMÉNEZ ESTEBAN, J. (1992-1993): Castillos de Guadalajara. Vol. I y II. Madrid. Acción Divulgativa.

JIMÉNEZ ESTEBAN, J. (1995): El castillo medieval español y su evolución. [Madrid (España)]. Agualarga.

JIMÉNEZ ESTEBAN, J. (2003): «Inventario de fortificaciones de Guadalajara». Castillos de España, $\mathrm{n}^{\circ} 130,49-52$.

LAYNA SERRANO, F. (1994): Castillos de Guadalajara. Cuarta edición. Guadalajara (España). Aache.

LAYNA SERRANO, F. (2006): La provincia de Guadalajara (descripción fotográfica de sus comarcas). [Guadalajara (España)]. Ediciones Bornova.

MALCOLM LEWIS, G. (1987): «The Origins of Cartography», en The History of Cartography/Volume One: Cartography in Prehistoric, Ancient, and Medieval Europe and the Mediterranean (Harley, J. B. y Woodward, D., eds.). Chicago, The University of Chicago Press, 50-53.

MALPICA CUELLO, A. (1998): «Los castillos en época nazarí: una primera aproximación», en Castillos y territorio en al-Andalus: Jornadas de arqueología medieval, Berja, 4, 5 y 6 de octubre de 1996 (Jornadas de Arqueología Medieval 1ª 1996 Berja). Granada (España), Athos-Pérgamos, 246-293.

MALPICA CUELLO, A. (2003): Los castillos en al-Andalus y la organización del territorio. Cáceres (España). Universidad de Extremadura, Servicio de Publicaciones. 
MONREAL Y TEJADA, L. (1999): Castillos medievales en España. Barcelona (España). Lunwerg.

ORTIZ GARCÍA, A., BALDOMINOS UTRILLA, R., CISNEROS GARCÍA, J., GÓMEZ GÓMEZ, R. M., LAINA RIAÑO, S., y PARDOS HERRER, S. (1998): Historia de Guadalajara. Guadalajara (España). Ayuntamiento de Guadalajara.

PARCERO-OUBIÑA, C., FÁBREGA-ÁLVAREZ, P., VICENT-GARCÍA, J. M., URIARTEGONZÁLEZ, A., FRAGUAS-BRAVO, A., BOSQUE-GONZÁLEZ, I. DEL, FERNÁNDEZ-FREIRE, C. y PÉREZ-ASENSIO, E. (2013): «Conceptual basis for a cultural heritage data model for INSPIRE». Revue Internationale de Géomatique/International Journal of Geomatics and Spatial Analysis, vol. 23/3-4, 445-467.

PEDRAZA RUIZ, P. y FRANCO VALLE, R. (2014): «Estrategias de gestión cultural en la arquitectura defensiva». Patrimonio Cultural de España, vol. 9, 197-206. Disponible en: http://en.calameo.com/read/000075335f44f4a8a51af

PERINAT ESCRIVÁ DE ROMANÍ, G. (2005): «Defensa del Patrimonio Castral Español: La labor de entidades sin ánimo de lucro como la Asociación Española de Amigos de los Castillos», en Simposio Internacional «Arquitectura fortificada»: Conservación, restauración y uso de los castillos (Cooper, E., coord.). Valladolid (España), Fundación del Patrimonio Histórico de Castilla y León, 351-398.

PROMOTION OF CULTURAL DIVERSITY IN KOSOVO TEAM (2012): Guidelines on Cultural Heritage - Technical Tools for Heritage Conservation and Management. [Pristina] (Kosovo). Council of Europe. Disponible en:

http://www.coe.int/t/dg4/cultureheritage/cooperation/kosovo/Publications/GuidelinesENG.pdf

RENNIE SHORT, J. (2003): The World through Maps: A History of Cartography. Toronto. Firefly Books Ltd.

RÍSQUEZ CUENCA, C. (1997): «Catalogación del Patrimonio Histórico (Cuadernos. Instituto Andaluz del Patrimonio Histórico)». Arqueología y Territorio Medieval, vol. 4, 243 246. Disponible en: http://revistaselectronicas.ujaen.es/index.php/ATM/issue/view/164

RIVERA BLANCO, J. (1999): «El patrimonio y la restauración arquitectónica. Nuevos conceptos y fronteras», en Patrimonio, restauración y nuevas tecnologías - PPU (Rivera, J., Altés, J., González Fraile, E., Sola, J. R., eds.). Valladolid, Instituto Español de Arquitectura, 17-28.

RODRÍGUEZ NUERE, B. (2014): «Necesidad y significación del Plan Nacional de Arquitectura Defensiva». Patrimonio Cultural de España, vol. 9, 19-28. Disponible en: http:// en.calameo.com/read/000075335f44f4a8a51af

RODRÍGUEZ PASCUAL, A., LÓPEZ ROMERO, E., ABAD POWER, P. y SÁNCHEZ MAGANTO, A. (2006): Modelo de Nomenclátor de España v1.2. [Madrid]. Consejo Superior Geográfico, Ministerio de Fomento. Disponible en:

http://www.diba.cat/documents/429764/429801/idebarcelona-fitxers-pdf-normativa-es_ mne-pdf.pdf

RUBIELLA ROMAÑACH, A. (2014): «Arquitectura defensiva o ingeniería militar, unas reflexiones». Patrimonio Cultural de España, vol. 9, 29-47. Disponible en:

http://en.calameo.com/read/000075335f44f4a8a51af

RUIBAL RODRÍGUEZ, A. (1992): Castillos de Guadalajara. León (España). Lancia. 
RUIBAL RODRÍGUEZ, A. y JIMÉNEZ ESTEBAN, J. (1997): «Castillos de Castilla-La Mancha», en Castillos de España, Tomo II: Castilla-La Mancha, Castilla y León (Bernad Remón, J., Coord.). León (España), Editorial Everest, 647-796.

SCOTT KELTIE, J. y HOWARTH, O. J. R. (1913): History of Geography. Londres. Watts \& $\mathrm{CO}$.

SEVILLA DE LERMA, M., IGUÁCEL ABEIGÓN, C. y ABAD POWER, P. (2008): «Sistemas de referencia e identificadores geográficos (ISO 19111, ISO 19112, ISO 6709) », en Introducción a la normalización en información geográfica: la familia ISO 19100 (Ariza López, F. J. y Rodríguez Pascual, A. F., Eds.). Jaén (España), Grupo de Investigación en Ingeniería Cartográfica, Universidad de Jaén, 59-74. Disponible en:

http://coello.ujaen.es/Asignaturas/pcartografica/Recursos/IntroduccionNormalizacion_ IG_FamiliaISO_19100_v2.pdf

SWIFT, M. (2006): Mapping the World. Edison (Nueva Jersey). Chartwell Books.

THORNES, R. y BOLD, J. (EDS.) (1998): Documenting the cultural heritage. Los Ángeles. Getty Information Institute. Disponible en: http://archives.icom.museum/objectid/heritage/index.html

UNITED NATIONS EDUCATIONAL, SCIENTIFIC AND CULTURAL ORGANIZATION (1972a): Convention concerning the Protection of the World Cultural and Natural Heritage 1972. París. United Nations Educational, Scientific and Cultural Organization. Disponible en: http://portal.unesco.org/en/ev.phpURL_ID=13055\&URL_DO=DO_ TOPIC\&URL_SECTION=201.html

UNITED NATIONS EDUCATIONAL, SCIENTIFIC AND CULTURAL ORGANIZATION (1972b): Recommendation concerning the Protection, at National Level, of the Cultural and Natural Heritage. París. United Nations Educational, Scientific and Cultural Organization. Disponible en: http://portal.unesco.org/en/ev.phpURL_ID=13087\&URL_ DO=DO_TOPIC\&URL_SECTION=201.html

UNITED NATIONS EDUCATIONAL, SCIENTIFIC AND CULTURAL ORGANIZATION (2013): Operational Guidelines for the Implementation of the World Heritage Convention. París. UNESCO World Heritage Centre. Disponible en: http://whc.unesco.org/ archive/opguide13-en.pdf

VARELA AGÜÍ, E. (2002): La fortaleza medieval: simbolismo y poder en la Edad Media. [Ávila (España)]. Junta de Castilla y León, Consejería de Educación y Cultura.

VELASCO, H. M. (2009): «El Patrimonio cultural como sistema de representación y como sistema de valor», en La protección jurídico internacional del patrimonio cultural: Especial referencia a España (Fernández Liesa, C. R. y Prieto de Pedro, J., Dir., Vacas Fernández, F. y Zapatero Miguel, P., Coord.). Majadahonda (Madrid), COLEX, 35-70.

VILLENA, L. (2001): «Arquitectura militar en la Península Ibérica», en Actas del IV Curso de Cultura Medieval: Seminario: La Fortificación Medieval en la Península Ibérica: Centro de Estudios del Románico, Aguilar de Campoo, 21-26 de septiembre de 1992 (Curso de Cultura Medieval $4^{\circ} 1992$ Aguilar de Campoo). Segunda Edición. Aguilar de Campoo (Palencia), Fundación Santa María la Real, 17-32.

WHALEN, T. P. (2013): «A Note from the Director». Conservation Perspectives, The GCI Newsletter, vol. 28-2,2. Disponible en:

http://www.getty.edu/conservation/publications_resources/newsletters/pdf/v28n2.pdf 